\title{
A CONSTRUÇÃo DA FRONTEIRA NACIONAL COMO MERCADO: TURISMO DE COMPRAS NA FRONTEIRA BRASIL/URUGUAI
}

\author{
Lúcia Helena Alves MÜLLER*
}

RESUMO: Esse trabalho aborda as dinâmicas sociais envolvidas no processo historicamente recente de constituição de um mercado de produtos globalizados na fronteira Brasil/Uruguai a partir da criação, em 2010, dos chamados free shops em algumas das cidades daquela região. Embora o comércio - legal e ilegal - faça parte dos fluxos que cruzam a linha divisória entre os dois países desde a sua formação, a recente criação das zonas de isenção fiscal propiciou o estabelecimento de novos circuitos do chamado turismo de compras. Além dos aspectos políticoslegais que os instituíram, o estabelecimento desses novos circuitos se baseia na atuação de uma grande diversidade de agentes que estão implicados na logística de transporte e hospedagem, na divulgação dos estabelecimentos comerciais e dos produtos, na orientação e fiscalização dos viajantes/consumidores em relação às regras aduaneiras, etc. A etnografia dessas dinâmicas nos permite identificar atores e processos envolvidos na construção da fronteira nacional como um mercado.

PALAVRAS-CHAVE: Fronteiras nacionais. Antropologia dos mercados. Antropologia do consumo.

\section{Introdução}

Esse trabalho aborda as dinâmicas sociais envolvidas no processo historicamente recente de constituição de um mercado de produtos globalizados na fronteira Brasil/Uruguai a partir da criação, em 2010, dos chamados free shops em algumas das cidades uruguaias daquela região.

PUC-RS - Pontifícia Universidade Católica do Rio Grande do Sul. Faculdade de Filosofia e Ciências Humanas. Departamento de Ciências Sociais. Porto Alegre - RS - Brasil. 90619-900 - lucia.helena@ pucrs.br. 
Núcleos e fluxos de comércio existem em diversos locais da fronteira do Brasil com os países vizinhos. Esses núcleos já foram alvo de importantes estudos que identificaram os agentes sociais que deles participam, descreveram as redes sociais e a rotas que possibilitam a circulação de mercadorias e investigaram a sua participação nos circuitos internacionais de pessoas e bens (DORFMAN, 2012 e 2009; RABOSSI, 2004a e 2004b; MARQUEZINI, 2010; PINHEIRO MACHADO, 2011). Esses trabalhos nos ajudaram a compreender a complexidade dos mercados de fronteira tal como o que tratamos aqui.

O que torna interessante voltarmos a essa temática é a peculiaridade do contexto em que se desenvolveu o circuito de compras na fronteira Brasil/Uruguai a partir da criação dos free shops, não apenas pela especificidade dessa região em termos de sua configuração histórica e cultural, mas principalmente porque, sendo um processo recente, podemos acompanhar praticamente a olho nu as dinâmicas sociais que estão constituindo esse novo mercado (ZELIZER, 2005). Num espaço de tempo muito curto, essas dinâmicas, que tiveram como catalizador a iniciativa do Estado uruguaio de permitir a criação dos free shops, mobilizaram uma ampla gama de agentes que produziram a oferta e também a demanda por um tipo muito especifico de produtos, na medida em que estabeleceram um mercado de serviços que garante o transporte, a hospedagem, o acompanhamento e orientação dos consumidores.

Assim, a análise de alguns dos processos sociais implicados no desenvolvimento do circuito de consumo da fronteira Brasil/Uruguai visa a contribuir para o conhecimento acerca dos processos de constituição social das fronteiras nacionais e também dos mercados (CARNEIRO, 2007; LAFERTÉ, 2008).

Por outro lado, na medida em que nos permite identificar os processos cognitivos, valorativos e estratégicos envolvidos nas escolhas realizadas, a observação de situações concretas de compras, ainda mais quando realizadas de uma forma intensiva como no caso dos viajantes/consumidores da fronteira Brasil/ Uruguai, também abre possibilidades para explorar o fenômeno do consumo como prática social (MILLER, 2002; BARBOSA et al. 2009; BARBOSA, 2004; GOIDANICH e MEZABARBA, 2014).

Esse artigo tem como referência dados que foram recolhidos em sites de agentes de turismo, de shoppings centers e de lojas situados na fronteira Brasil/ Uruguai. Baseia-se ainda em observações que foram realizadas ao longo de 2016 e 2017, em excursões de compras que partiam de Porto Alegre, dirigindo-se à cidade uruguaia de Rivera, gêmea da brasileira Santana do Livramento. ${ }^{1}$

\footnotetext{
1 O levantamento e sistematização dos dados da internet, bem como em algumas das excursões a campo tiveram a participação de Nayara Anhanha Silva, bolsista de iniciação científica da FAPERGS.
} 


\section{A construção da fronteira nacional como mercado: turismo de compras na fronteira Brasil/Uruguai}

\section{Fronteiras: limites e fluxos}

Fronteiras nacionais podem ser consideradas instituições totais, pois sua existência implica as mais diversas dimensões da vida social: territorial, política, econômica, simbólica. As fronteiras nacionais também são instituições muito vivas, já que seu estabelecimento se baseia em processos sociais complexos e permanentes que envolvem conflitos, tensionamentos, negociações e acordos entre diversos atores sociais (estados nacionais, governos regionais, instituições e populações locais).

As dinâmicas envolvidas na construção das fronteiras nacionais são muito evidentes nas localidades que se constituíram ao longo do tempo como pontos de passagem de pessoas e mercadorias e também onde há uma população estabelecida que compartilhou processos históricos significativos. São mais evidentes ainda quando junto à linha divisória entre os países existem conglomerados urbanos contínuos, como no caso das chamadas cidades-gêmeas (SÁNCHES, 2002; SANTOS, 2006).

É o que acontece com as fronteiras Brasil/Uruguai e Brasil/Argentina. A definição da linha divisória entre o Brasil e esses dois países, assim como a própria constituição do Uruguai como nação, resultaram das mesmas guerras e negociações (GOLIN, s/d). A linha de fronteira do Rio Grande do Sul com o Uruguai e com a Argentina é muito maior do que a extensão da divisa desse estado com o estado de Santa Catarina, que o conecta com os demais estados brasileiros, sendo que a fronteira do Uruguai como o Brasil situa-se inteiramente no território do estado do Rio Grande do Sul. Junto à linha de fronteira entre esses países existem diversos núcleos urbanos contíguos e uma população estabelecida que compartilha largamente seus padrões culturais, além de transitar com grande fluidez entre os idiomas e dialetos vigentes (português, espanhol, portunhol). Além disso, no estado do Rio Grande do Sul a identidade gaúcha se constituiu em contraste ou mesmo em oposição à identidade brasileira (OLIVEN, 2006). Todos esses aspectos ajudam-nos a compreender porque o estado do Rio Grande do Sul como um todo é percebido como fronteiriço, e porque a noção de fronteira é um elemento tão essencial na conformação do imaginário dos habitantes dessa região, a ponto deles se perceberem como partilhando a cultura da fronteira.

A quase inexistência de barreiras físicas entre o Brasil e o Uruguai permitiu, desde os primórdios da formação dos dois países, um fluxo constante - legal e ilegal de pessoas, de gado e de mercadorias (DORFMAN, 2009 e 2012). O montante e a direção desses fluxos sempre oscilaram de acordo com as variações cambiais e de preços que tornavam vantajosa a compra de bens e serviços de uso cotidiano (gasolina, alimentação, móveis, eletrodomésticos, vestuário, etc.), ora em um, ora em outro país. 
A oscilação na direção do fluxo de comércio envolvendo a população local e o comércio estabelecido nas cidades da fronteira entre Brasil e Uruguai segue acontecendo. Além disso, em alguns pontos de passagens (Chuí/Chuy, Jaguarão/ Rio Branco, Livramento/Rivera) que se constituíram como rotas tradicionais para destinos mais longínquos no interior de cada um dos países estabeleceu-se já há mais tempo um comércio dirigido especificamente aos viajantes. Entretanto, a partir de 2010, quando o governo uruguaio autorizou a criação dos free shops nessas e em outras localidades, novas dinâmicas comerciais se evidenciaram na região. A criação das zonas de isenção fiscal propiciou o estabelecimento de novos circuitos do chamado turismo de compras.

A ação do governo uruguaio tinha como objetivo promover o crescimento de oportunidades econômicas na região da fronteira com o Brasil. A instalação desses centros de compras nas cidades uruguaias gerou, por sua vez, reações nas comunidades fronteiriças do lado brasileiro, que passaram a pressionar o governo federal para obterem o licenciamento para a instalação de centros similares no Brasil e promoverem mudanças nas regras de isenção fiscal estabelecidas até então ${ }^{2}$. A autorização para a criação de free shops em cidades brasileiras foi obtida em 2012, mas sua implantação ainda não foi totalmente regulamentada e vem sendo adiada desde então.

Assim, num curto período de tempo, diversas cidades uruguaias situadas na fronteira com o Brasil ${ }^{3}$ criaram centros de comércio de produtos que participam dos circuitos globais de mercadorias cotadas em dólar norte-americano que são oferecidas a viajantes não uruguaios com isenção de tributos (bebidas, cosméticos, eletrônicos, perfumes, acessórios e artigos de vestuário de marcas com prestígio internacional, etc.). A criação de free shops no lado uruguaio da fronteira fez com que os núcleos urbanos em que eles se instalaram, assim como as cidades brasileiras próximas, tivessem um crescimento expressivo de visitantes que têm como principal objetivo de sua viagem a compra dos produtos oferecidos nesse tipo específico de comércio.

Ao contrário do comércio tradicional, que tinha os habitantes e comerciantes locais como seus principais clientes, grande parte dos frequentadores das lojas free shops provêm de outras cidades do estado do Rio Grande do Sul e de outros estados do Brasil. A instalação desse mercado implicou, assim, o crescimento de visitantes inclusive em localidades que não faziam parte das rotas tradicionais de passagem entre os dois países nem eram vistas como locais de especial interesse

\footnotetext{
2 A proposta é a de que a quota de isenção fiscal para compras nos free shops uruguaios, que é de US $\$ 300$, seja repartida, passando para US\$150 de isenção para compras no Uruguai e US $\$ 150$ para compras nos free shops brasileiros a serem instalados.

3 As cidades uruguaias que possuem free shops são: Aceguá, Artigas, Bella Unión, Chuy, Rio Branco e Rivera.
} 


\section{A construção da fronteira nacional como mercado: turismo de compras na fronteira Brasil/Uruguai}

turístico. Além dos aspectos políticos-legais de sua instauração, o estabelecimento desses novos circuitos se baseia na atuação de uma grande diversidade de agentes que estão implicados na logística de transporte e hospedagem, na divulgação dos estabelecimentos comerciais e dos produtos, na orientação e fiscalização dos viajantes/consumidores em relação às regras aduaneiras, etc.

\section{Turismo de compras}

As cidades gêmeas Santana do Livramento/Rivera formam um conglomerado urbano único e sem barreiras que limitem a circulação de pedestres ou de carros entre o território do Brasil e o do Uruguai. No lado uruguaio é que se encontra o comércio voltado para o turismo de compras. As lojas free shop se espalham em alguns quarteirões centrais da cidade de Rivera que podem ser esquadrinhados a pé, e também em dois grandes shoppings centers que se localizam em zonas mais afastadas cujo acesso exige transporte específico.

Durante os finais de semana, sobretudo quando a cotação do dólar está mais favorável para os brasileiros, a cidade fica lotada com turistas que vêm de diversas cidades do Rio Grande do Sul e, em menor número, de outros estados do Brasil. Nas ruas estreitas da região central de Rivera, já de madrugada pode-se escutar o movimento de ônibus e vans em busca de um lugar para estacionar. Este não pode ser muito afastado do centro de comércio pois os veículos deverão ficar à espera do embarque das mercadorias que os viajantes trarão ao longo de sua jornada de compras.

Uma das características do turismo de compras, pelo menos nas cidades da fronteira Brasil/Uruguai, é que raramente a viagem é feita por indivíduos avulsos. Em geral, quem vai aos free shops são familiares que se deslocam conjuntamente, às vezes em mutirões de compras que são organizados com antecedência, tendo prioridades previamente definidas. Grupos de amigos e conhecidos também se programam tendo um objetivo comum (bebidas para uma festa, por exemplo). Alguns indivíduos participam dessas viagens apenas para colaborar com o projeto, fornecendo a sua cota de isenção fiscal.

Muitas pessoas viajam em excursões organizadas, sendo comum que familiares, colegas de trabalho e grupos de amigos combinem de se acompanhar nessas viagens de compras que podem acontecer sob a forma de comboios de automóveis ou através da contratação de empresas que oferecem pacotes que incluem o transporte e a hospedagem. Em Santana do Livramento, alguns hotéis participam desses pacotes e oferecem a seus hóspedes transporte gratuito para levalos até os shoppings centers que se localizam em Rivera, longe do centro da cidade. 
Mas, nos últimos anos, o que movimenta de fato as ruas de comércio das cidades uruguaias da fronteira com o Brasil é o público trazido por excursões rodoviárias que são organizadas de forma periódica para quem se dispõe a viajar exclusivamente para fazer compras. Essas excursões costumam ser oferecidas pelas empresas com uma certa regularidade (uma vez por mês) e de forma extraordinária na véspera de datas especiais como natal, páscoa, dia das mães, dia das crianças.

As excursões de compras partem de diversas cidades do estado do Rio Grande do Sul e funcionam no esquema conhecido como bate-e-volta, isto é, os viajantes não pernoitam na cidade. Quando partem de lugares distante, as viagens são noturnas e chega-se à fronteira ao amanhecer. Depois de um percurso que pode durar entre 2 e 12 horas, dependendo da cidade de origem, os passageiros têm entre 5 e 7 horas para realizarem as compras antes de iniciarem a viagem de volta. Com exceção de alguns pacotes que oferecem café da manhã e também o acesso às instalações sanitárias em algum hotel, esses passageiros têm os ônibus em que viajam como única referência e apoio na cidade.

A divulgação dessas excursões é feita através da internet, em sites de agências de turismo e de empresas de transporte rodoviário. Também encontramos anúncios de excursões colados em locais públicos (postes, paradas de ônibus urbanos) e publicados em jornais ou pequenas publicações que são distribuídas gratuitamente. O Facebook e o aplicativo WhatsApp também são muito utilizados pelos agentes de viagem para se comunicarem com os viajantes costumazes que já fazem parte da sua clientela.

As agências de viagem geralmente utilizam ônibus ou vans fretadas. Empresas de transporte rodoviário regular e empresas que possuem uma frota de veículos para frete também organizam excursões específicas para compras. As viagens partem dos próprios terminais das empresas ou de algum estacionamento próximo à estação rodoviária da cidade de origem.

É muito difícil contabilizar o número de pessoas envolvidas nesse circuito de consumo. Ele já foi muito grande no período entre a época da implantação dos free shops, em 2010, e o ano de 2014, quando o real estava muito valorizado frente à moeda norte-americana. Sofreu forte queda ao longo de 2015 e 2016 em razão da crise econômica e da desvalorização da moeda brasileira frente ao dólar, mas, segundo depoimentos dos agentes de viagem, voltou a crescer moderadamente ao longo de 2017. Atualmente, podemos apenas estimar o volume do turismo de compras na cidade de Rivera observando o movimento dos ônibus de excursões que estacionam frente a um restaurante localizado à margem da principal rodovia que liga Porto Alegre a Santana do Livramento, utilizado como ponto de descanso por muitas das empresas envolvidas nesse tipo de turismo. Apesar da crise econômica que assola o Brasil e do câmbio não muito favorável para quem usa o Real, em 


\section{A construção da fronteira nacional como mercado: turismo de compras na fronteira Brasil/Uruguai}

maio de 2017, durante a madrugada de um sábado próximo ao dia das mães (época considerada propícia para compras), em torno de 15 ônibus de grande porte se encontravam estacionados naquele local para que seus passageiros jantassem.

Em geral, os preços cobrados pelas excursões são mais baixos do que o cobrado pela mesma viagem realizada em um ônibus regular. Mesmo assim, eles variam conforme o tempo de uso e o padrão de conforto do veículo utilizado. Algumas excursões utilizam ônibus muito novos, com poltronas que reclinam como leitos. Também oferecem lanches e filmes para distração dos passageiros. Outras usam veículos mais antigos, sem maiores confortos ou cuidados com a manutenção. Essas oferecem um serviço de bordo muito simples (água, café).

A diversidade na qualidade do serviço e o preço cobrado pelas excursões corresponde claramente à diferenciação socioeconômica dos passageiros. E essa diferenciação corresponde a uma hierarquia moral construída a partir de uma apreciação acerca da relação dos indivíduos com a atividade de consumo. Assim é que, embora grande parte dos viajantes comprem produtos com o objetivo de revendê-los (voltaremos a esse ponto), é evidente o esforço por parte dos que têm maior poder aquisitivo no sentido de se distinguir daqueles que são percebidos como compradores de produtos baratos ou considerados de má qualidade, assim como dos consumidores profissionais (pagos para trazerem mercadorias para terceiros) ou dos que dependem economicamente dessa atividade. "O preço que cobramos é mais alto porque nós não levamos moambeiros", foi o que informou a funcionária de uma agência de turismo, ao justificar o alto valor que sua empresa cobrava pela excursão.

\section{Produtos da fronteira}

Durante décadas, as cidades situadas nas fronteiras Brasil/Uruguai e Brasil/ Argentina abasteceram a população rio-grandense e também os viajantes oriundos de outros estados do Brasil com artigos de couro e de lã (cobertores, confecções), vinhos, laticínios, doces elaborados com leite ou com frutas, quase todos originários dos dois países platinos.

Hoje em dia esses produtos ainda são comercializados. Os laticínios são oferecidos em pequenas lojas ou armazéns e as roupas de lã, em pequenas lojas de confecções com uma apresentação muito tradicional. Mas já não se encontra mais cobertores de lã, que perderam a concorrência para as mantas e cobertores de origem chinesa, feitos de material sintético.

O que pode surpreender a quem anda pela região central da cidade de Rivera é encontrar, entre as lojas free shop situadas na principal rua comercial, uma espécie de loja-museu, testemunha do tempo em que os produtos de lã eram valorizados 
e em que a durabilidade dos produtos era vista como uma qualidade positiva, em contraste gritante com o atual padrão de consumo, em que são valorizados os produtos de marcas globais e em que um dos principais motores do consumo é a obsolescência dos produtos em função da acelerada dinâmica do código da moda e das inovações tecnológicas. O proprietário dessa loja é herdeiro do que já foi um importante lanifício, mas, segundo afirma, hoje vive de rendas e mantém a loja apenas como um hobby.

Assim é que em um espaço comercial cuja fachada não tem adereços para chamar a atenção dos passantes, grandes rolos de tecido de lã de diversas cores e estampas são expostos sobre um estrado de madeira que ocupa praticamente toda a extensão da loja. As prateleiras laterais a esse estrado estão repletas de objetos antigos (caixas registradoras, calculadoras, recipientes de uso domésticos, instrumentos musicais, ferramentas) que foram doados por moradores, comerciantes e industriais da região que sabiam que o proprietário dessa loja iria conserválos. Nem os tecidos de lã nem os objetos antigos estão à venda. As mercadorias comercializadas são os palas de lã escura, confeccionados segundo um modelo muito tradicional da indumentária típica gaúcha que, segundo uma atendente da loja, podem durar 30 anos, fato que justificaria o preço relativamente alto cobrado pelo artigo. Também estão à venda palas confeccionados com tecido sintético de diversas cores. Conforme o proprietário da loja, esses produtos são oferecidos ali exclusivamente para ajudar as costureiras que os confeccionam.

Nas ruas centrais de Rivera também pode-se encontrar lojas, pequenos centros de compras e também vendedores ambulantes que oferecem produtos de baixo preço produzidos na China (roupas, mantas, brinquedos, acessórios para a casa, aparelhos eletrônicos). Encontramos ainda lojas que vendem confecções produzidas na Índia e outras onde são oferecidos aparelhos de ar condicionado e pneus.

Existem lojas especializadas em produtos de baixo custo (confecções, cobertores, artigos de cozinha, algumas marcas de bebidas e eletrônicos). Nelas, os artigos são expostos sem muita ordem e limpeza, sendo comum que sejam apresentados nas mesmas caixas de papelão que os embalavam quando chegaram às lojas. Algumas delas contratam divulgadores que, vestidos de forma a chamar a atenção (usam perucas coloridas, roupas de palhaço, etc.), ficam na calçada apregoando as ofertas através de megafones.

Já as grandes lojas free shop estabelecidas em Rivera fazem parte de redes que têm filiais nas cidades de Chuy e Rio Branco e também são proprietárias ou estão presentes nos shoppings centers da cidade. Nessas lojas, que têm uma decoração cuidada similar às lojas dos free shops presentes em aeroportos de todo o mundo, encontramos uma enorme quantidade de produtos com origens diversas (países europeus, Estados Unidos, Índia, China), mas que têm em comum o fato de 


\section{A construção da fronteira nacional como mercado: turismo de compras na fronteira Brasil/Uruguai}

participarem do mercado global de marcas consideradas de alto padrão (aparelhos, eletrônicos, roupas, calçados, perfumes, cosméticos, artigos de cozinha, chocolates, biscoitos, alimentos processados do tipo delicatessen e uma grande variedade de bebidas). Essas mercadorias são precificadas em moeda norte-americana e vendidas por um preço relativamente elevado.

\section{As boas compras}

O fato de se disporem a mobilizar recursos econômicos, tempo e esforços para chegarem a esses locais de comércio nos leva a supor que os frequentadores dos free shop detêm algum grau de conhecimento acerca dos produtos oferecidos e, também, capacidade de os apreciar, isto é, de avaliar se a aquisição desses produtos compensa o investimento e os esforços empreendidos.

As informações sobre produtos e preços circulam entre os participantes desses grupos e as avaliações sobre o que vale a pena comprar, ou não, costumam ter como referência os familiares, amigos ou companheiros de jornada. Na decisão sobre a compra também entra em jogo a capacidade de apreciação acerca das variações da cotação do câmbio entre as moedas envolvidas nesse mercado e também das regras que regulam o uso do cartão de crédito (WEBER, 2011).

A procura por alguns dos produtos disponíveis nas cidades da fronteira tem uma variação claramente sazonal: compra-se muitos cobertores sintéticos e chaleiras elétricas no inverno, muitos aparelhos de ar condicionado e ventiladores no verão, e uma grande quantidade de bebidas (espumantes, vinhos) no período anterior às festas de final de ano.

Nas excursões que fizemos a Rivera pudemos encontrar indivíduos que demonstram uma grande desenvoltura na apreciação e escolha de produtos sofisticados. São pessoas com renda alta que provavelmente já viajaram ao exterior e frequentaram lojas free shops de aeroportos internacionais. Esses indivíduos conhecem o mapa das marcas e os padrões globais da moda. Esse tipo de consumidor é capaz de andar por todas as lojas free shop da cidade e passar em revista os incontáveis estandes em que são expostas as marcas mais prestigiosas de perfumes, cosméticos, tênis ou bebidas até resolver-se sobre a aquisição de determinados produtos. Nesses casos, a diferença dos preços não é o critério principal para a decisão pela compra (a vantagem em relação ao preço do produto vendido no Brasil já está dada pela isenção fiscal que incide sobre os free shops) e sim a especificidade do produto em pauta no que se refere à marca, ao modelo ou à coleção a que pertencem.

Por outro lado, encontramos pessoas de aparência muito simples que buscavam por produtos que elas mesmas não conheciam ou cujo nome, anotado em 
um papel, elas não sabiam pronunciar. Tratava-se de encomendas feitas por quem financiou a viagem. Na época das festas de final de ano, esse tipo de comprador de bebidas por encomenda é mais comum, embora eles também estejam presentes em outros períodos do ano, fornecendo bebidas e produtos alimentícios para donos de restaurantes e promotores de eventos de todo o estado.

Entre esses extremos há uma grande variedade de viajantes/consumidores. Nas lojas que vendem produtos baratos, eles formam longas filas na calçada, para conseguirem entrar na loja, ou em frente às caixas registradoras, na saída. Essas pessoas compram produtos para si, para os parentes e também para revender.

Independentemente do nível econômico dos viajantes, a grande maioria dos frequentadores das excursões de compras revendem os artigos adquiridos nessas viagens, mesmo que esse comércio tenha como único objetivo financiar o custo da viagem ou envolver apenas familiares, vizinhos ou colegas de trabalho. Alguns fazem as viagens para obter uma renda extra, contando com uma clientela que é formada a partir de sua inserção profissional, como acontece com quem trabalha em salões de beleza, com pessoas que trabalham em repartições públicas, que atuam como professores, etc. Tem ainda aqueles viajantes que são pagos para buscar mercadorias específicas para abastecer lojas e revendedores de todas as categorias, das butiques mais refinadas aos sacoleiros e camelôs, além de restaurantes e lojas especializadas em delicatessen. Nesses casos, a decisão sobre as compras leva em consideração principalmente o preço que poderá ser alcançado na revenda do produto no Brasil.

\section{Os mediadores}

Para que ocorra o encontro entre a oferta dos produtos nas cidades fronteiriças do Uruguai e os consumidores brasileiros uma figura exerce um papel muito importante: o guia das excursões. São pessoas que conhecem os caminhos, os serviços oferecidos nas cidades de destino, as regras do controle aduaneiro, e que acompanham a dinâmica das oportunidades de compras na fronteira (o que vale a pena comprar, onde achar, os preços, o câmbio, etc.).

A atividade dos guias de excursões é muito intensa. Eles viajam com muita frequência para diversos centros de compras (Rivera, cidade de São Paulo, algumas cidades do estado de Santa Catarina e de Minas Gerais, Ciudad del Leste, no Paraguai). Esses profissionais trabalham com as empresas de turismo e de transporte, nem sempre mantendo um vínculo permanente com elas. Sua reputação frente aos clientes é, portanto, fundamental para a sua sobrevivência nesse mercado. Quando o guia tem uma clientela fiel, pode levá-la consigo quando se transfere de uma 


\section{A construção da fronteira nacional como mercado: turismo de compras na fronteira Brasil/Uruguai}

empresa para outra. Por isso, eles atendem aos viajantes de uma maneira muito pessoalizada e gentil, buscando estabelecer laços e garantir sua presença em novas viagens.

Além de orientar os turistas nas suas jornadas de compras, os guias são responsáveis pela organização das bagagens nos ônibus pois dela depende não só a agilidade na devolução dos volumes no retorno à cidade de origem, mas principalmente a gestão da relação com a fiscalização, numa eventual parada no controle aduaneiro. Em todas as excursões de que participamos, durante a viagem de ida os guias reforçavam a importância do respeito às regras estipuladas pela Receita Federal. Já na volta, eles buscavam colocar-se de forma neutra em relação a pequenas transgressões praticadas pelos passageiros, embora tentassem controlar maiores abusos para que sua reputação frente aos fiscais não fosse atingida. Numa das viagens que realizamos, nosso ônibus carregava um grande excedente de bagagem e só foi liberado pela fiscalização depois de alguns momentos de grande tensão. O guia atribui a boa-vontade demonstrada pelos fiscais ao fato dele não ter tentado disfarçar o deslize ocorrido no controle da quantidade de mercadorias, o que demonstrava a lisura com que desempenhava a sua atividade profissional.

\section{Considerações finais}

Os circuitos de pessoas e mercadorias que se formam em torno das fronteiras nacionais é uma temática complexa, sendo assim, nesse artigo, procuramos fazer apenas uma primeira abordagem dos dados obtidos até aqui, com o objetivo de mapear os agentes e as dinâmicas envolvidos nas transformações que aconteceram na fronteira entre Brasil e Uruguai a partir da criação e instauração dos free shops, em 2010.

Vimos que, ao longo de toda a sua história, essa região foi perpassada por uma infinidade de fluxos de pessoas, animais, mercadorias, dinheiro, etc., e que esses fluxos se constituíram a partir de configurações políticas, econômicas e culturais definidas em diversos planos: o plano dos interesses geopolíticos e das relações formais entre os Estados nacionais, o plano dos interesses e identidades definidos em nível regional e local, e o plano da convivência cotidiana das populações que ali habitam. Essas configurações constituíram os diversos contextos a partir dos quais os fluxos foram estimulados ou refreados, reconhecidos como legais e legítimos, ou não, e produziram padrões de cooperação, de concorrência e de conflito entre as populações envolvidas.

No processo recente que analisamos aqui, o governo uruguaio foi o motor das mudanças através da legislação que permitiu a instalação de lojas free shops 
nas cidades da fronteira com o Brasil. A ação governamental visava estimular o investimento comercial e a criação de empregos na região uruguaia da fronteira. $\mathrm{O}$ sucesso dessa iniciativa dependia, no entanto, da criação da demanda pelos produtos oferecidos por esse comércio, que não existia localmente e que foi criada a partir da iniciativa de agentes econômicos brasileiros, mobilizando empresas e trabalhadores de diversas cidades que passaram a se dedicar à prestação dos serviços de transporte, acolhimento e orientação de consumidores brasileiros. Assim, podemos dizer que a ação do governo uruguaio estimulou, não apenas o crescimento do comércio em suas cidades da fronteira, mas também o desenvolvimento de um mercado de serviços do lado brasileiro que se estende por todo o território do Rio Grande do Sul.

Todo esse processo fez crescer o comércio de artigos que não são produzidos na região da fronteira nem nos países nela implicados. Trata-se de produtos cuja especificidade não está em sua procedência nem em seu pertencimento a um repertório cultural particular. Eles compõem um universo de artigos que, embora possam eventualmente ser valorizados por estarem associados a uma tradição particular (perfumes e vinhos franceses, uísques escoceses, artigos esportivos de determinadas marcas europeias ou norte-americanas, por exemplo), podem ser produzidos e comprados em qualquer lugar do mundo, fazendo parte de uma gramática de marcas e modelos que ordena o mundo do consumo globalizado (ORTIZ, s/d). Esses produtos têm seus preços definidos por um mercado global e comercializados em dólar norte-americano. E, em contraste com o comércio tradicional dessas cidades, que ainda mantêm especificidades locais, as lojas free shops seguem um padrão de apresentação similar em todos os locais onde se instalam mundo a fora, podendo ser classificadas como não-lugares, conforme a definição de Marc Augé (1992).

As cidades brasileiras envolvidas nesse circuito tiveram algum ganho econômico com o crescimento do movimento de viajantes que se dirigem à fronteira. Elas também reivindicaram que o governo brasileiro legislasse de forma a permitir a criação de free shops no lado de cá da fronteira. Essa legislação foi criada, mas os free shops brasileiros ainda não foram implementados na prática. Além disso, em algumas dessas cidades os governos, juntamente com empresários e outros agentes da sociedade local, passaram a buscar formas de desenvolver e divulgar as atrações turísticas da região, de forma a canalizar o interesse dos frequentadores dos free shops uruguaios, retendo-os ao menos por algum tempo no lado brasileiro da fronteira. Muitos atrativos que as cidades da fronteira brasileira com o Uruguai têm a oferecer aos turistas estão relacionados aos costumes e práticas (alimentares, musicais, produtivas) consideradas típicas do que se conhece como cultura da fronteira, em um claro contraste com a experiência desterritorializada proporcionada pelo turismo de compras do circuito dos free shops. 
Vemos, assim que, de uma situação em que os fluxos de pessoas e produtos entre os dois países se definiam com base nos contrastes relacionados às especificidades nacionais (entre legislações, entre padrões nacionais de desenvolvimento econômicos e seus reflexos no valor relativo de suas respectivas moedas) ou na possibilidade de um compartilhamento de identidades e de vivências cotidianas por parte das populações que vivem nas cidades-gêmeas, produziu-se um novo contexto que atrela essas regiões aos circuitos globalizados de bens de consumo. Essa mudança partiu de uma iniciativa governamental unilateral mas depende absolutamente da dinâmica econômica dos dois países envolvidos e, sobretudo, da manutenção da fronteira funcionando como um limite (monetário e fiscal) entre eles.

Com essa primeira abordagem sobre o tema, descobrimos que os estudos sobre a criação social dos mercados têm muito a contribuir para o conhecimento da instituição das fronteiras nacionais no mundo contemporâneo.

\section{THE ESTABLISHMENT OF THE NATIONAL BORDER AS A MARKET: SHOPPING TOURISM ON THE BRAZIL/URUGUAY BORDER}

ABSTRACT: This work addresses the social dynamics involved in the historically recent process of establishing a globalized product market on the Brazil/Uruguay border, as a result of the creation, in 2010, of so called free shops in some of the cities in that region. Although trade - legal and illegal - is part of the flows that cross the dividing line between the two countries since their formation, the recent creation of tax free zones has led to the establishment of new circuits called "shopping tourism". In addition to the legal and political aspects that instituted them, the establishment of these new circuits is based on the action of diverse agents that are involved in the logistics of transportation and lodging; in the promotion of shops and products; in the guidance and inspection of travelers/ consumers in regards to customs rules, etc. The ethnography of these dynamics allows us to identify actors and processes implicated in the establishment of the frontier as a market.

KEYWORDS: National border. Anthropology or markets. Anthropology of consumption. 


\section{REFERÊNCIAS}

AUGÉ, Marc. Non-lieux: introduction à une anthropologie de la surmodernité. Paris, Seul, 1992.

BARBOSA, L. et al. (Org.) Consumo: cosmologias e sociabilidades. Rio de Janeiro, Mauad X; Seropédica, RJ, EDUR, 2009.

BARBOSA, L. Sociedade de consumo. Rio de Janeiro, Zahar, 2004.

CARNEIRO, M. A construção social do mercado de madeiras certificadas na Amazônia brasileira: a atuação das ONGs ambientalistas e das empresas pioneiras. Sociedade e Estado, v. 22, n. 3, p. 681-713. set./dez. 2007.

DORFMAN, A. Representações, normas e lugares? Contos de contrabando na fronteira gaúcha. Para Onde!? v. 6, n 2, p. 102-113, jul./dez. 2012.

. A cultura do contrabando e a fronteira como lugar de memória. Estudios Historicos - n.1, maio 2009.

GOIDANICH, M. E.; MEZABARBA, S. (Orgs.). Etnografias possíveis: experiências etnográficas sobre consumo no ambiente urbano. Rio de Janeiro, Ponteio, 2014.

GOLIN, Tau. A fronteria: governos e movimentos espontâneos na fixação dos limites do Brasil com o Uruguai e a Argentina. Porto Alegre, L\&PM, e-book, s/d.

LAFERTÉ, Gilles. Imagem social ou luta política e cultural pelo controle do mercado. Mana, Rio de Janeiro, v. 14, n. 2, p. 399-427, out. 2008.

MARQUEZINI, Ana Carolina T. Circuitos espaciais de fronteira: cidades gêmeas de Foz do Iguaçu e Cidade do Leste. Entre-Lugar, ano 1, n. 2, p. 33-55, $2^{\circ}$ semestre 2010.

MILLER, D. Teoria das compras: o que orienta as escolhas dos consumidores. São Paulo, Nobel, 2002.

OLIVEN, Ruben G. A parte e o todo: a diversidade cultural no Brasil- nação. Petrópolis, Vozes, 2006.

ORTIZ, Renato. Um outro território: ensaios sobre a mundialização. São Paulo, Olho D'água, $\mathrm{s} / \mathrm{d}$.

PINHEIRO MACHADO, Rosana. Made in China: (in)formalidade, pirataria e redes sociais na rota China-Paraguai-Brasil. São Paulo, Hucitec/Anpocs, 2011.

RABOSSI, F. Dimensões da espacialização das trocas: a propósito de mesiteros e sacoleiros em Ciudad del Este. Ideação, v. 6. p. 151-176, 2004a. 
RABOSSI, F. Nas ruas de Ciudad del Este: vidas e vendas num mercado de fronteira Tese (Doutorado em Antropologia Social), Universidade Federal do Rio de Janeiro, Museu Nacional, Programa de Pós-Graduação em Antropologia Social, 2004b.

SÁNCHEZ, Andrea Q. A fronteira inevitável: um estudo sobre as cidades da fronteira de Rivera (Uruguai) e Santana do Livramento (Brasil) a partir de uma perspectiva antropológica. Tese de doutorado. Porto Alegre, PPG Antropologia Social UFRGS, 2002.

SANTOS, Ana Rosa D. dos. A organização social das fronteiras: etnografia do cotidiano fronteiriço Chuí/Chuy. Dissertação de Mestrado. Brasília, Centro de Pesquisa e PósGraduação sobre as Américas. 2006.

WEBER F. Calculs économiques. Genèses, nº 84, p. 2-5, 2011.

ZELIZER, V. Circuits within capitalism. In: NEE, V.; SWEDBERG, R. (Eds.). The economic sociology of capitalism. Princeton: Princeton University Press, 2005.

Recebido em 14/08/2017.

Aprovado em 28/11/2017. 
